\title{
Pelagic longline gear depth and shoaling
}

\author{
Keith Bigelow $^{\mathrm{a}, *}$, Michael K. Musyl ${ }^{\mathrm{b}}$, Francois Poisson ${ }^{\mathrm{c}}$, Pierre Kleiber ${ }^{\mathrm{a}}$ \\ ${ }^{a}$ Pacific Islands Fisheries Science Center, NOAA Fisheries, 2570 Dole Street, Honolulu, HI 96822, USA \\ ${ }^{\mathrm{b}}$ Joint Institute for Marine and Atmospheric Research, University of Hawai'i at Manoa, 2570 Dole Street, Honolulu, HI 96822, USA \\ c IOTC, Indian Ocean Tuna Commission, PO Box 1011, Victoria, Mahe, Seychelles
}

Received 14 February 2005; received in revised form 22 August 2005; accepted 3 October 2005

\begin{abstract}
Temperature-depth recorders (TDRs) were attached to pelagic longline gear in the Hawaii-based commercial fishery to obtain actual fishing depths and to test the accuracy of catenary algorithms for predicting fishing depths. Swordfish gear was set shallow by typically deploying four hooks between successive floats. The observed depth of the settled deepest hook had a median value of $60 \mathrm{~m}$ for $333 \mathrm{swordfish}$ sets. Tuna longline gear deployed more hooks between floats (mean $=26.8$ ), and the observed median depth of the deepest hook was $248 \mathrm{~m}(n=266 \mathrm{sets}$ ). Maximum gear depth was predicted from estimates of the longline sag ratio and catenary algorithms; however, depth was not predicted for all TDR-monitored sets because estimating sag ratios proved problematic. Swordfish sets had less slack in the main line and correspondingly smaller catenary angles $\left(\right.$ median $\left.=54.2^{\circ}\right)$ than tuna sets $\left(\right.$ median $\left.=63.7^{\circ}\right)$. Median values of the predicted catenary depth were $123 \mathrm{~m}$ for swordfish sets $(n=203)$ and $307 \mathrm{~m}$ for tuna sets $(n=198)$. Shallow swordfish sets reached only $\sim 50 \%$ of their predicted depth, while deeper tuna sets reached about $70 \%$. These values indicated that capture depths using traditional catenary equations may be biased without the benefit of TDRs affixed to longlines. Generalized linear models (GLMs) and generalized additive models (GAMs) were developed to explain the percentage of longline shoaling as a function of predicted catenary depth and environmental effects of wind stress, surface current velocity, and current shear. The GAM explained $67.2 \%$ of the deviance in shoaling for tuna sets and $41.3 \%$ for swordfish sets. Predicted catenary depth was always the initial variable included in the stepwise process, and the inclusion of environmental information in the GAM approach explained an additional 10-17\% of the deviance compared to the GLMs. The explanatory ability of the environmental data may have been limited by the scale of the observations ( $1^{\circ}$ in space; weekly or monthly in time) or the geometric (transverse versus in-line) forcing between the environment and longline set. Longline gear models with environmental forcing affecting shoaling may be improved in future studies by incorporating contemporaneous environmental information, although this may restrict analyses to fine-scale experimental longlines.
\end{abstract}

Published by Elsevier B.V.

Keywords: Temperature-depth recorders; Fishing depth; Bycatch; Pelagic fishes; Longline fisheries; Catenary algorithms

\section{Introduction}

The depth at which species are captured is fundamental to understanding the impacts of longline fisheries on target and bycatch species. Accurate gear and capture depths lead to significant improvements in fishery oceanographic relationships, vertical distribution, habitat preferences, and stock assessments (Boggs, 1992; Brill and Lutcavage, 2001). In order to account for the variability in catch rates, fisheries investigators routinely correlate catch-per-unit-of-effort

\footnotetext{
* Corresponding author. Tel.: +1 808983 5388; fax: +1 8089832900 .

E-mail address: Keith.Bigelow@noaa.gov (K. Bigelow).
}

(CPUE) with environmental factors such as sea surface temperature; however relationships are often poorly defined (Squire, 1985, 1987; Herron et al., 1989; Podestá et al., 1993) or inconclusive (Power and May, 1991). The lack of significant relationships may result from neglecting the variability in catch rates by depth, which results in a mismatch between catch rates and explanatory variables (Podestá et al., 1993).

Pelagic stock assessments utilize longline fishery data as indices of abundance. Longline CPUE data are routinely standardized to remove biases associated with catchability and availability of the resource. The depth-related bias in catchability can be corrected in various standardization procedures including (1) empirical approaches (e.g. general linear 
models (GLMs)) that directly attempt to account for the variation in catch or CPUE as a function of depth or gear type (Allen and Punsley, 1984) and (2) deterministic approaches such as habitat-based standardizations whereby effective effort is modeled as the joint probability of the vertical distribution of hooks in the water column and the distribution of the species (Hinton and Nakano, 1996). Improved estimates of gear behavior, fishing depth, and a species vertical distribution will reduce the uncertainty in assessments due to catchability.

Trying to ascertain the optimal fishing depths for commercially important pelagic species caught on longlines has been attempted with vertical longlines (Saito et al., 1970; Saito, 1973, 1975), sonar (Bullis, 1955), chemical sounding tubes (Graham and Stewart, 1958), expendable bathy-thermographs (XBTs, Laurs et al., 1981), micro-BTs (Mizuno et al., 1996, 1998, 1999; Okazaki et al., 1997), depth recorders (Saito, 1973; Hanamoto, 1974; Nishi, 1990), and temperature-depth recorders (TDRs; Boggs, 1992; Bach et al., 2003). In addition to these trial surveys, other studies (e.g. Hanamoto, 1987; Suzuki et al., 1977; Gong et al., 1989; Grundinin, 1989; Ward et al., 1996; Nakano et al., 1997) have calculated hook depths with gear configuration and catenary geometry (Yoshihara, 1951, 1954), as theory predicts that a suspended line with equal vertical loading along its length will assume the shape of a catenary in the absence of corrupting factors.

While hook depths can be inferred through catenary geometry, actual depths are confounded by environmental factors that shoal the longline and reduce targeted fishing depths. Shoaling has been estimated by monitoring the depth of experimental longline gear (Hanamoto, 1974; Nishi, 1990; Boggs, 1992; Mizuno et al., 1998, 1999). Estimated catenary depths are typically from 170 to $190 \mathrm{~m}$ for shallow gear with five branchlines and hooks deployed between successive floats (HBF) in the Japanese longline fishery. Empirically, the deepest hook on shallow gear was found to range from 100 to $160 \mathrm{~m}$ (Hanamoto, 1974) and 122 to $178 \mathrm{~m}$ (Nishi, 1990) corresponding to mean shoaling estimates of $\sim 24 \%$ and $\sim 11 \%$, respectively. Shoaling averaged $10 \%$ for deeper gear targeting albacore tuna from 100 to $350 \mathrm{~m}$ (Saito, 1973); however, observed and predicted depths differed greatly on 38 sets targeting tuna (12-20 HBF, 225-450 m) near the Hawaiian Islands (Boggs, 1992). During the two years of the Boggs' experiments, observed depths averaged only $54 \%$ and $68 \%$ of predicted depths or shoaling estimates of $46 \%$ and $32 \%$, respectively. Mizuno et al. $(1998,1999)$ estimated the threedimensional underwater shape of longlines with concurrent oceanographic conditions of currents monitored by an acoustic Doppler current profiler (ADCP). Accurate observations of the sagging or shortening ratio were necessary to define the mainline shape and depth. Longline shape and shoaling depended on vertical current shear relative to the main line rather than absolute current velocity.

This study documents TDR monitoring to compare observed and predicted fishing depths in the commercial
Hawaii-based longline fishery. We used TDRs deployed on swordfish and tuna longline gear to verify the efficacy of catenary algorithms. Longline shoaling was modeled as a function of catenary depth and associated mesoscale oceanographic and meteorological variables.

\section{Materials and methods}

Longline depth was monitored on sets in the central North Pacific $\left(5-40^{\circ} \mathrm{N}, 127-174^{\circ} \mathrm{W}\right)$ from February 1996 to April 1999. On 59 longline trips, fishery observers of the National Marine Fisheries Service (NMFS) attached single TDRs (Wildlife Computers; models MK2 and MK3e) to the middle position on the main line between two floats where, in theory, the gear should be at its deepest point (Bigelow et al., 2002, Fig. 1). Since only a single TDR was placed on each set, we assumed that the attachment point was the deepest point of the catenary and that other sections of the gear had a maximum value similar to the monitored section. In order to reduce fluctuation effects near the end of the longline, the TDR was attached after at least 10 floats had been set.

Depth was monitored on shallow gear targeting swordfish and deep gear targeting bigeye tuna. These gear types differ primarily in the length of monofilament main line and hooks deployed between successive floats (HBF). Swordfish gear is characterized as the 'Gulf of Mexico' style (Ito et al., 1998) which typically deployed four HBF and is kept relatively taut to target the upper 30-90 m of water column (Boggs and Ito, 1993). Tuna fishing used a line thrower to put sag in the longline and deployed a greater number of $\mathrm{HBF}$ to reach depths of $\sim 400 \mathrm{~m}$ (Boggs, 1992).

The TDRs were programmed to measure temperature and depth every $5 \mathrm{~min}$. Portions of each profile were truncated to allow for setting and retrieval of the longline. This typically corresponded to the first and last $30 \mathrm{~min}$ of a tuna set and 15 min of a swordfish set. Sharp vertical movements in a profile typically correspond to a fish being hooked adjacent to a TDR (Okazaki et al., 1997), and these data were also deleted. For each profile, maximum hook depth was calculated by adding branchline length and TDR depth. Statistics were calculated for the maximum settled hook depth, mean settled maximum hook depth (observed depth), and a standard deviation of settled hook depth.

\subsection{Catenary depth estimation}

Predicted maximum depth was based on catenary algorithms (Yoshihara, 1951, 1954). The catenary parameter $u$ is initially solved by iteration as

$u=\sinh \left(\frac{u}{S}\right)$

where $S$ is the sag ratio or stretched length of the main line deployed between two floats $(L)$ divided by the horizontal distance between two successive floats $(H)$. Previous studies 
have used the reciprocal of $S$ (i.e. $H / L$ ) to express the sag ratio, but we have chosen the current metric as smaller or larger values correspond to lesser and greater sag ratios. $S$ was estimated by two methods. In the first method, $L$ was estimated by the vessel operator as the amount of mainline length fished, and $H$ was the great circle distance based on the latitude and longitude coordinates at the start and end of each set. The second method estimated $S$ as the ratio of the speed of the line thrower to vessel speed; however, the speed of the line thrower was estimated on only a portion of the monitored longline sets $(n=47)$. The remaining sets were assumed to have an average line speed deployed at 9.25 knots based on observer data from 1994 to 2002 ( $n=1272$, S.D. $=1.54$ knots, range $=5-14$ knots). Method 1 was used to estimate $S$ for swordfish sets as the fishers did not use a line thrower. Both methods were used to estimate $S$ for tuna sets. The angle $(\phi)$ between the horizontal and tangential line of the main line where the floatline was attached (degrees from horizontal) was taken from the relationship:

$\phi=a \tan (u)$

The catenary angle could not be estimated for all TDRmonitored sets. Appropriate angles were considered as $30-85^{\circ}$ which corresponded to sag ratios ranging from 1.04 to 3.57. Catenary depths were not estimated for sets with sag ratios outside of this range.

The depth of catenary hooks was estimated as

$$
\begin{aligned}
D_{j}= & h_{\mathrm{a}}+h_{\mathrm{b}}+0.5 L \\
& \times\left\{\left(1+\cot ^{2} \phi\right)^{1 / 2}-\left[\left(1-2 \frac{j}{N}\right)^{2}+\cot ^{2} \phi\right]^{1 / 2}\right\}
\end{aligned}
$$

where $D_{j}$ is the depth of catenary hook $(j), h_{\mathrm{a}}$ the length of branch line, $h_{\mathrm{b}}$ the length of float line, $j$ the number of the catenary hook midway between floats and $N$ is $\mathrm{HBF}+1$.

\subsection{Environmental covariates}

Longlines are expected to deviate from predicted catenary depth due to environmental effects such as current velocity, shear, and wind. Environmental covariates were obtained to explore the relationship with longline behavior. Observers recorded precise locations for the start and end of the longline set, though the longline was set over a geographical distance of $\sim 30 \mathrm{~nm}$. A mesoscale approach was taken in linking environmental data given the geographical resolution of the longline and the large spatial range over which the fishery operates. Longline location was defined as the midpoint of the set.

Ocean surface currents were obtained from two ocean models and derived from satellite altimetry data; wind stress was obtained from remote sensing scatterometer. Current velocities were obtained from a coupled ocean-atmosphere model developed at the National Centers for Environmental
Prediction (NCEP; Behringer et al., 1998). The model has 27 vertical layers $(0-3000 \mathrm{~m})$ with the first layer $(5 \mathrm{~m})$ representing surface velocity. The model has a spatio-temporal resolution of $1^{\circ}$ latitude and $1.5^{\circ}$ longitude by 1 month (1996-1997) or week (1998-1999). Current velocities indicative of a $30 \mathrm{~m}$ surface layer were obtained from the ocean surface current analyses-real time (OSCAR) model (Bonjean and Lagerloef, 2002). The near-surface velocity was derived directly from sea surface height, wind velocity, and sea surface temperature as the sum of a geostrophic term, wind-diffusion term, and buoyancy-gradient term. The OSCAR model has a spatio-temporal resolution of $1^{\circ}$ by 10 day. Geostrophic currents approximating the upper $100 \mathrm{~m}$ mixed layer were derived from sea surface height from TOPEX-POSEIDON satellites (Aviso dataset; Picot et al., 2003). Geostrophic computations followed Polovina et al. (1999) with derived currents having a spatio-temporal resolution of $0.5^{\circ}$ by 10 day. Wind stress (Pascals) at each fishing location was obtained from the European Remote Sensing (ERS) satellite's wind scatterometer. The ERS model has a spatio-temporal resolution of $1^{\circ}$ by 1 week.

Current shear throughout the water column may also influence longline behavior. The vertical shear of the horizontal current component was estimated by integrating from the near-surface to the catenary depth, $z$, as

$K=\log \left(\frac{\int_{0}^{z}\left\|\frac{\partial \vec{u}}{\partial z}\right\| \mathrm{d} z}{Z}\right)$

The integral is approximated by

$\tilde{K}=\log \left\{\frac{\sum_{n=1}^{N}\left[\left(\frac{u_{n+1}-u_{n}}{z_{n+1}-z_{n}}\right)^{2}+\left(\frac{v_{n+1}-v_{n}}{z_{n+1}-z_{n}}\right)^{2}\right]^{1 / 2}\left(z_{n+1}-z_{n}\right)}{\sum_{n=1}^{N}\left(z_{n+1}-z_{n}\right)}\right\}$

where $\tilde{K}$ is the log-transformed vertical shear, $u_{n}$ the zonal velocity component of layer $n, v_{n}$ the meridional velocity component of layer $n$, and $z_{n}$ is the depth of layer $n$. Vertical shear was estimated from the NCEP model by integrating from 5 to $120 \mathrm{~m}$ (12 layers) for swordfish sets and from 5 to $430 \mathrm{~m}$ (20 layers) for tuna sets.

\subsection{Modeling longline shoaling}

General linear models (GLMs) and generalized additive models (GAMs) were developed to explain the percentage of longline shoaling [100 $\times(1-$ observed depth/predicted depth)] as a function of predicted catenary depth and environmental effects. Longline shoaling was modeled in a GLM framework as a function of catenary depth with up to a third order (cubic) effect without environmental effects. GAMs were developed to explain longline shoaling as a function of catenary depth, wind stress, surface current velocity (NCEP, OSCAR or Aviso), and current shear. Initial analysis considered wind stress and surface current as separate components 
parallel and perpendicular to the longline, but these were eventually combined because separating the components did not yield any significant increase in explanatory ability. A GAM was based upon cubic splines (Venables and Ripley, 1999) and each explanatory variable was given five nonlinear degrees of freedom, which is equivalent to a more flexible polynomial regression with four degrees of freedom. GLM and GAMs were fit in forward and backward selection, and the best predictive model was based on the Akaike Information Criteria. Sequential $F$-tests evaluated if terms were significant with a $P<0.01$ entry criterion.

\section{Results}

TDR data were obtained on a total of 599 longline sets. Longline sets were characterized into distinct swordfish and tuna gear types based on the number of hooks between floats (HBF). Swordfish sets $(n=333)$ deployed two to six HBF (mean $=4.3$ ) while tuna sets $(n=266)$ deployed 20-32 HBF $($ mean $=26.8)$. Attributes of the TDR-monitored swordfish and tuna gear are given in Table 1.

\subsection{Catenary and observed depth estimation}

Catenary angle and depth were not predicted for all TDR-monitored longline sets because estimated sag ratios were outside the range of 1.04-3.57. Catenary angle and depth were predicted for 203 swordfish sets $(61 \%)$ based on estimating a sag ratio by the length of main line fished (method 1, Table 2). Catenary depth was predicted for $74 \%$ ( $n=198$ sets) of tuna sets based on method 1. A larger percentage was predicted for method $2(95 \%, n=255$ sets $)$, although most $(n=218)$ of the values for the speed of the line thrower were assumed. Swordfish sets had smaller sag ratios $($ median $=1.22)$ than tuna sets $($ method $1:$ median $=1.39$, method 2: median $=1.32$ ). The distribution of sag ratios was skewed for swordfish sets as small sag ratios from 1.05 to 1.35 represented $67 \%$ of the total (Fig. 1A). In comparison, the distribution of sag ratios for tuna sets decreased from 1.05 to 2.5 (Fig. 1F) and were normally distributed for method 2. Given less slack in the mainline, swordfish sets had correspondingly smaller catenary angles $\left(\right.$ median $\left.=54.2^{\circ}\right)$ than tuna sets $\left(\right.$ method $1:$ median $=63.7^{\circ}$, method 2: median $=60.4^{\circ}$ ). Median values of the predicted catenary depth were $123 \mathrm{~m}$ for swordfish sets and 307 and $303 \mathrm{~m}$ for tuna sets based on methods 1 and 2 , respectively (Table 2 ).

The observed TDR depth of the settled deepest hook had a median value of $60 \mathrm{~m}$ for swordfish sets (Table 2) with $90 \%$ of the sets shallower than $100 \mathrm{~m}$ (Fig. 1D). The observed depth had a median value of $248 \mathrm{~m}$ for tuna sets with $95 \%$ of the sets deeper than $100 \mathrm{~m}$ (Fig. 1I). Observed set depth was usually less than predicted catenary depth (Fig. 2); however, observed depth was deeper than catenary depth for $5 \%$ of swordfish sets, $29 \%$ of tuna sets estimated by method 1 (Fig. 2) and $21 \%$ of tuna sets estimated by method 2 (not illustrated).
Table 1

Average, S.D. and range (in parentheses) of longline attributes among 333 swordfish and 266 tuna longline sets monitored with temperature-depth recorders (TDR) in the Hawaii-based fishery from February 1996 to April 1999

\begin{tabular}{|c|c|c|}
\hline \multirow[t]{2}{*}{ Variable } & \multicolumn{2}{|l|}{ Longline set type } \\
\hline & Swordfish (shallow) & Tuna (deep) \\
\hline $\begin{array}{l}\text { Line shooter } \\
\text { (nmi/h) }\end{array}$ & No & $\begin{array}{l}\text { Yes, } 9.06 \pm 2.15(6-12) \\
n=47 \text { sets }\end{array}$ \\
\hline $\begin{array}{l}\text { Vessel speed } \\
\quad(\mathrm{nmi} / \mathrm{h})\end{array}$ & $7.67 \pm 0.85(6-10)$ & $6.70 \pm 0.71(4-9)$ \\
\hline Start set time (h) & $1639 \pm 0548(0015-2358)$ & $\begin{array}{l}0755 \pm 0121 \\
(0531-1730)\end{array}$ \\
\hline Soak time (h) & $1936 \pm 0244(11-28)$ & $1906 \pm 0222(13-31)$ \\
\hline Hooks per set & $777 \pm 170(225-1200)$ & $1729 \pm 363(776-2772)$ \\
\hline $\begin{array}{l}\text { Hooks between } \\
\text { floats }\end{array}$ & $4.3 \pm 0.6(2-6)$ & $26.8 \pm 2.5(20-32)$ \\
\hline Floats per set & $183.3 \pm 39.5(56-300)$ & $69.7 \pm 13.2(33-118)$ \\
\hline Floatline (m) & $10.3 \pm 7.0(3-36)$ & $20.9 \pm 6.1(9-45)$ \\
\hline Branchline (m) & $16.4 \pm 5.4(7-48)$ & $13.4 \pm 4.6(6-27)$ \\
\hline Mainline (km) & $74.5 \pm 14.6(18.5-111.1)$ & $\begin{array}{l}64.4 \pm 19.9 \\
(27.8-111.1) \text {-method } 1\end{array}$ \\
\hline$L(\mathrm{~m})$ & $415 \pm 76(257-712)$ & $\begin{array}{l}962 \pm 261 \\
(499-1764)-\text { method } 1\end{array}$ \\
\hline $\begin{array}{l}\text { Mainline diameter } \\
(\mathrm{mm})\end{array}$ & $3.8 \pm 0.4(2.9-5.0)$ & $3.5 \pm 0.3(2.8-4.0)$ \\
\hline No. lightsticks/set & $397 \pm 224(0-1000)$ & $\begin{array}{l}98.5 \% \text { n.a., } 1.5 \% \text { (four } \\
\text { sets) had a range of } \\
40-60\end{array}$ \\
\hline Lightstick color & $\begin{array}{l}44 \% \text { Mixed, } 40 \% \text { green, } \\
4 \% \text { yellow, } 12 \% \text { n.a. }\end{array}$ & $98.5 \%$ n.a., $1.5 \%$ green \\
\hline Line weights (g) & $64.7 \pm 12.2(30-80)$ & $51.8 \pm 13.1(21-80)$ \\
\hline Hook type & $\begin{array}{l}86 \% \text { Mustad "J", } 12 \% \\
\text { offset (Mustad "J"), } 2 \% \\
\text { other }\end{array}$ & $\begin{array}{l}91 \% \text { Japan style tuna } \\
\text { hooks, } 9 \% \text { other }\end{array}$ \\
\hline Hook size & $\begin{array}{l}4 \% \text { "8/0", 92\% “9/0", 4\% } \\
\text { "10/0" }\end{array}$ & $\begin{array}{l}5 \% \text { “8/0", } 4 \% 3.4 \\
\text { (Japanese size system), } \\
91 \% 3.6 \text { (Japanese size } \\
\text { system) }\end{array}$ \\
\hline Bait & $\begin{array}{l}68 \% \text { "Large" squid, } 26 \% \\
\text { "small" squid, } 6 \% \text { mixed }\end{array}$ & $\begin{array}{l}95 \% \text { Saury (Cololabis } \\
\text { saira), } 3 \% \text { Mackerel } \\
\text { (Scomber japonicus), } \\
2 \% \text { other }\end{array}$ \\
\hline
\end{tabular}

n.a.: data not available.

Catenary depths were shallower than observed depths when sag ratios were estimated to be small $(<1.15)$.

Swordfish sets reached an average of $49 \%$ of their predicted depth corresponding to a shoaling percentage of $51 \%$ (Table 2). Tuna sets reached an average of $86 \%$ and $79 \%$ of their predicted depth based on methods 1 and 2, respectively (Table 2). Median values of shoaling percentage were always larger than mean values. Mean shoaling estimates for tuna sets based on method $1(14 \%)$ are less than method $2(21 \%)$ because the distribution is negatively skewed with a long tail representing catenary depths that are shallower than observed depths (Fig. 1H). If data are deleted when predicted catenary depths are shallower than observed depths, then mean shoaling estimates increased to $55 \%$ for swordfish sets, $39 \%$ for tuna sets estimated by method 1 , and 32\% for tuna sets estimated by method 2 (Table 2). 
Table 2

Mean, S.D., median and range (in parentheses) of gear configuration and the deepest hook of longline sets monitored with temperature-depth recorders (TDR) in the Hawaii-based fishery from February 1996 to April 1999

\begin{tabular}{|c|c|c|c|}
\hline \multirow[t]{3}{*}{ Variable } & \multicolumn{3}{|l|}{ Longline set type } \\
\hline & \multirow[t]{2}{*}{ Swordfish (shallow) } & \multicolumn{2}{|l|}{ Tuna (deep) } \\
\hline & & Method 1 & Method 2 \\
\hline Sag rate & $1.51 \pm 0.66,1.22(1.04-3.65, n=203)$ & $1.49 \pm 0.39,1.39(1.04-2.54, n=198)$ & $1.40 \pm 0.16,1.32(1.14-2.31, n=255)$ \\
\hline Catenary angle, $\phi$ & $56.4 \pm 15.6^{\circ}, 54.2^{\circ}(28-85, n=203)$ & $60.2 \pm 15.4^{\circ}, 63.7^{\circ}\left(27-81^{\circ}, n=198\right)$ & $62.7 \pm 6.7^{\circ}, 60.4^{\circ}\left(46-80^{\circ}, n=255\right)$ \\
\hline $\begin{array}{l}\text { Predicted depth of deepest } \\
\text { hook }(\mathrm{m})\end{array}$ & $140.0 \pm 48.1,123.0(69-301, n=203)$ & $342.7 \pm 158.7,306.6(115-779, n=198)$ & $319.6 \pm 82.7,302.7(144-681, n=255)$ \\
\hline TDR depth (m)—all & $63.9 \pm 28.9,59.8(15-178, n=333)$ & $243.6 \pm 83.2,248.0(60-504, n=266)$ & Same as method 1 \\
\hline $\begin{array}{l}\text { TDR depth }(\mathrm{m}) \text { with valid } \\
\text { predicted catenary depth }\end{array}$ & $62.3 \pm 28.2,57.6(23-178, n=203)$ & $248.5 \pm 87.8,253.2(60-462, n=198)$ & $244.8 \pm 83.9,248.4(60-504, n=255)$ \\
\hline $\begin{array}{l}\text { Maximum TDR depth } \\
\text { (m)—all }\end{array}$ & $94.7 \pm 42.5,91.9(16-284, n=333)$ & $302.4 \pm 92.4,307(69-614, n=266)$ & Same as method 1 \\
\hline $\begin{array}{l}\text { Maximum TDR depth }(\mathrm{m}) \\
\text { with valid predicted } \\
\text { depth }\end{array}$ & $91.5 \pm 39.7,86.4(26-223, n=203)$ & $304.4 \pm 97.3,311(69-518, n=198)$ & $303.6 \pm 93.3,307(69-614, n=255)$ \\
\hline $\begin{array}{l}\text { Standard deviation }(\mathrm{m}) \text { of } \\
\text { settled TDR depth-all }\end{array}$ & $14.5,9.1(0-49, n=333)$ & $33.9,29.8(4-111, n=266)$ & Same as method 1 \\
\hline $\begin{array}{l}\text { Shoaling percentage—all } \\
\text { predicted depth }\end{array}$ & $51.1 \pm 26.0,56.9(-65-87, n=203)$ & $14.1 \pm 48.5,29.1(-166-85, n=198)$ & $20.5 \pm 29.1,24.3(-66-84, n=255)$ \\
\hline $\begin{array}{l}\text { Shoaling } \\
\text { percentage—positive } \\
\text { shoaling only }\end{array}$ & $55.1 \pm 19.0,58.6(3-87, n=193)$ & $39.1 \pm 19.3,39.8(1-85, n=141)$ & $31.8 \pm 19.0,30.5(0-84, n=203)$ \\
\hline TDR SST $\left({ }^{\circ} \mathrm{C}\right)$ & $20.5 \pm 3.1,19(15.9-29.7, n=311)$ & $25.6 \pm 1.4,25.6(20.9-28.4, n=266)$ & Same as method 1 \\
\hline $\begin{array}{l}\text { Minimum TDR } \\
\text { temperature }\left({ }^{\circ} \mathrm{C}\right)\end{array}$ & $18.1 \pm 4.2,17.7(6-27, n=311)$ & $12.6 \pm 3.8,11.6(6.1-25.8, n=266)$ & Same as method 1 \\
\hline
\end{tabular}

Gear configuration for tuna longline sets was estimated by two methods (see text).

\subsection{Modeling longline shoaling}

Results on modeling longline shoaling are presented for three GLMs and three GAMs (Table 3). The explanatory ability for shoaling was highest for tuna longline sets estimated by method 1 (GLM $R^{2}=0.573$, GAM $\left.R^{2}=0.672\right)$, intermediate for swordfish sets $\left(\mathrm{GLM} R^{2}=0.246, \mathrm{GAM} R^{2}=0.413\right)$, and lowest for tuna longline sets estimated by method 2 (GLM $R^{2}=0.200$, GAM $R^{2}=0.347$ ). The inclusion of environmental information in the GAM approach explained an additional $10-17 \%$ of the deviance compared to the GLMs. Catenary depth, wind stress, and current shear were significant $(P<0.0001)$ in the GAMs, and catenary depth was always the initial variable included in the stepwise process.

The GAM for swordfish sets included catenary depth, shear, and wind stress, but surface current velocity was not significant $(P=0.246)$. Current shear was of secondary importance and explained an additional $10 \%$ of the variance (Table 3). The relative effects of the variables are largest for catenary depth and intermediate for shear and wind stress (Fig. 3). Shoaling increased slightly from low to moderate current shear but was reduced at high shear values $(\sim-6.5)$. The effect of wind stress was generally complex. Shoaling decreased when wind stress increased from 0 to $0.15 \mathrm{~Pa}$. The trend in shoaling increased at higher wind stress values, though confidence intervals are wide given the lack of data. The GLM for swordfish sets included catenary depth as a second order component to estimate shoaling (Table 3 ).
Shoaling was estimated to increase from $\sim 20 \%$ at a depth of $70 \mathrm{~m}$ to a maximum value of $\sim 70 \%$ at $200 \mathrm{~m}$ with a slight decline in shoaling at greater depths.

The GAMs for tuna sets included all explanatory variables, but the order of inclusion differed from the swordfish analysis as wind stress was preferred by the model over shear and current velocity (Table 3). Relationships between explanatory variables and shoaling were similar for the two methods used to estimate catenary depth, but results are illustrated only for method 1 given the model's higher explanatory ability and the additional assumption for estimating the sag ratio in method 2. The effect of wind stress and current shear was similar to the swordfish analysis, although the effects appear minimal because the magnitude of the $y$-axis is larger for the tuna longline analysis (Fig. 4). Shoaling decreased with increasing wind stress to a value of $0.125 \mathrm{~Pa}$ and increased thereafter. There was a general trend for an increase in shoaling with higher current velocity and higher shear; however, the increase was slight, and $95 \%$ confidence bands typically overlapped throughout the range of observations. Current velocity from the Aviso dataset was included in each GAM for tuna sets, but there was little difference in explanatory ability with the other two (NCEP, OSCAR) products. The GLMs for tuna sets included catenary depth as a third (method 1) or second (method 2) order component (Table 3). For method 1 , shoaling was estimated to increase from $0 \%$ at a depth of $200 \mathrm{~m}$ to a maximum value of $\sim 50 \%$ at $400 \mathrm{~m}$ with a similar rate at deeper depths. GAMs developed for the swordfish and 
Swordfish sets
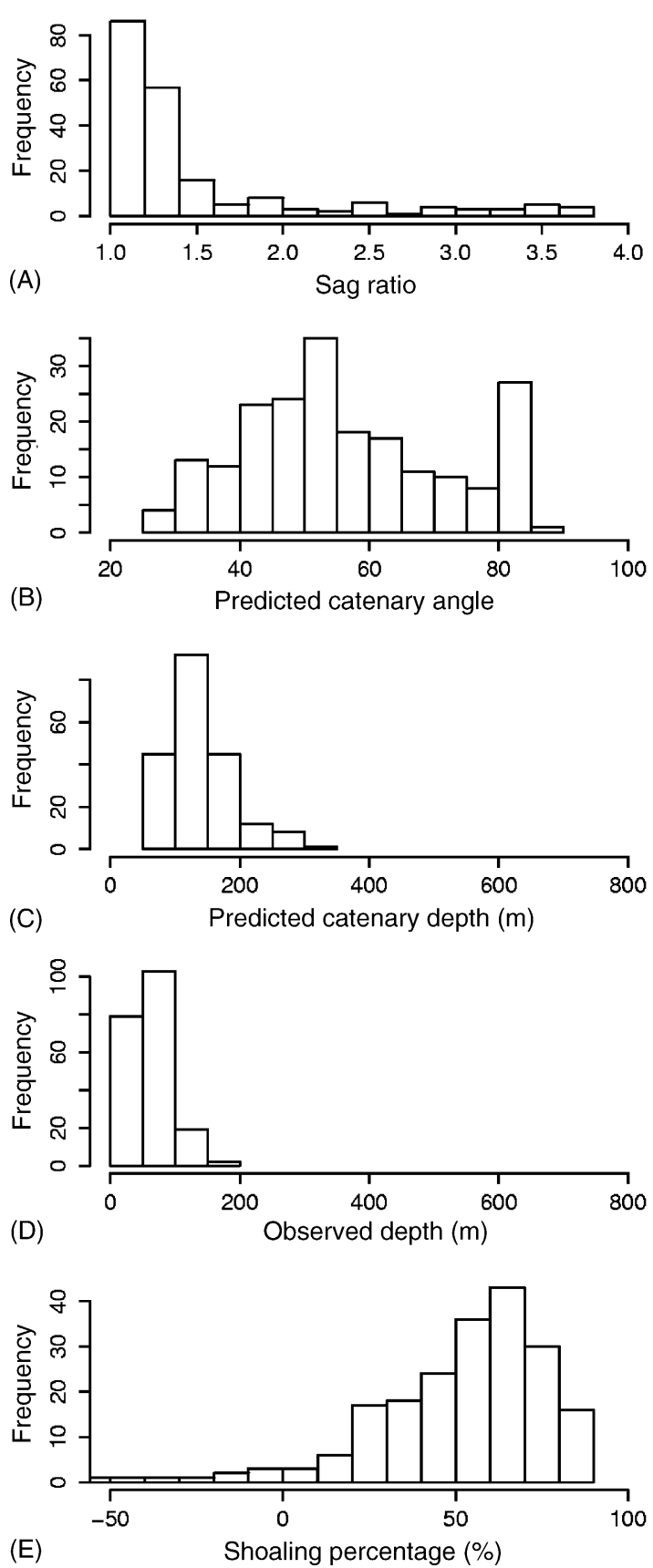

Tuna sets
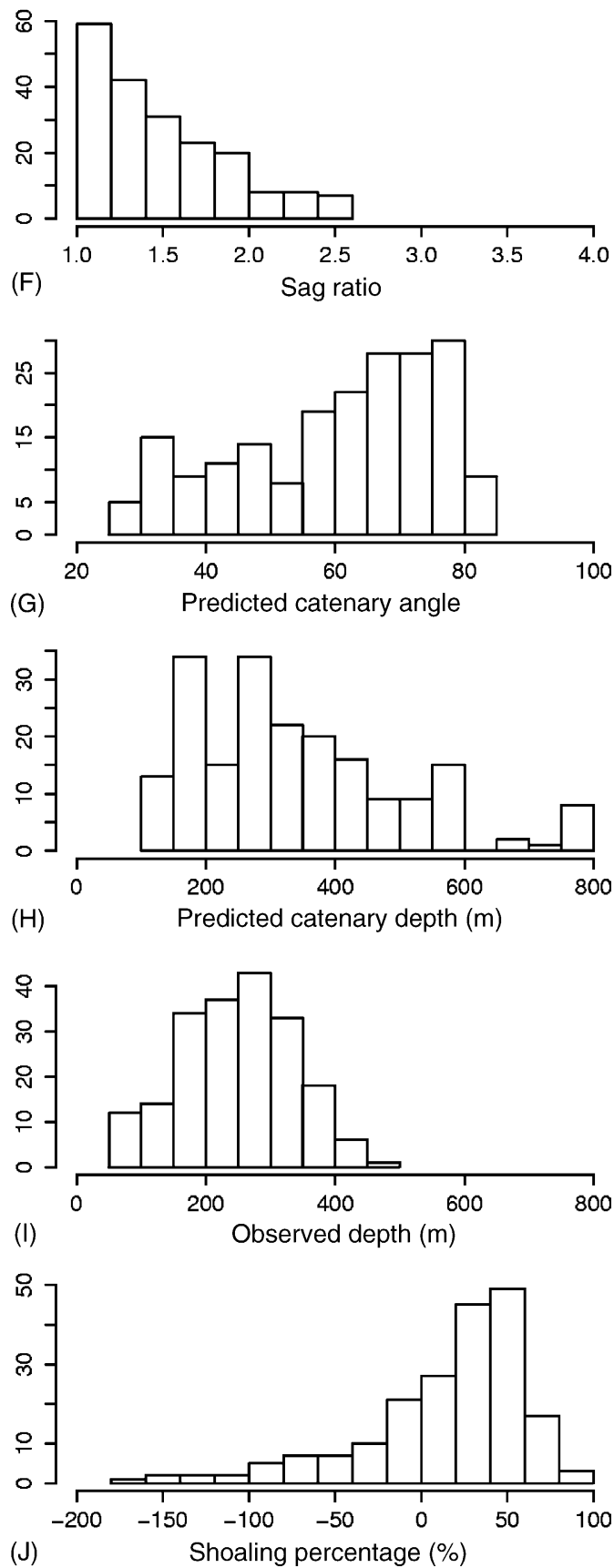

Fig. 1. Sag rate, predicted catenary angle, catenary depth, observed depth, and shoaling percentage for swordfish and tuna longline sets. Catenary depth estimated by method 1 for tuna longline sets.

tuna sets (method 1) were used to produce shoaling predictions for comparison with observed TDR depth. Points are clustered around the expected $45^{\circ}$ angle (Fig. 5).

\section{Discussion}

Depth monitoring of the Hawaii-based longline fishery indicates a clear delineation between swordfish and tuna gear at $\sim 100 \mathrm{~m}$. Virtually all swordfish effort was shallower than $100 \mathrm{~m}$ as the depth of the observed deepest hook averaged $64 \mathrm{~m}$. Tuna longline gear deploys more hooks between floats, and the average depth of the deepest hook was $244 \mathrm{~m}$. Although the study did not interpolate the depth of hooks shallower than the deepest hook, most of the tuna-targeted effort is deeper than $100 \mathrm{~m}$. Assumptions in monitoring longline depth include that (1) the monitored section had a similar maximum depth as other longline sections and (2) TDRs were attached at the deepest point of the catenary. Addressing these assumptions requires TDRs being placed on sequential hooks 


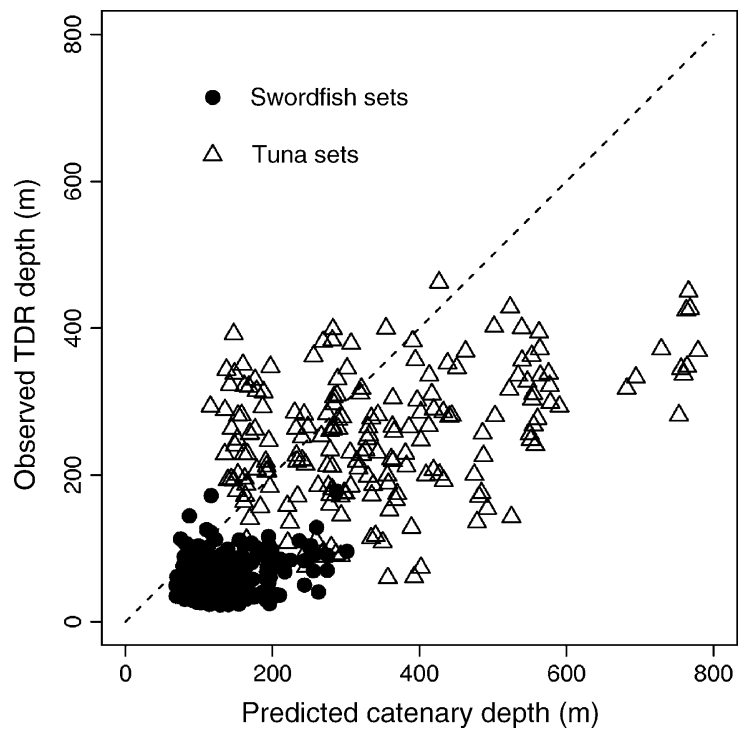

Fig. 2. Comparison of predicted catenary depth and observed depth for swordfish and tuna longline sets.

and at deepest points on different longline sections. This was beyond the scope of monitoring the commercial fishery; however, monitoring of experimental longlines provides some evidence that these assumptions are valid. Eighteen experimental longlines with five HBF targeting swordfish were monitored with TDRs (M. Musyl, unpublished data, Uni- versity of Hawai'i at Manoa, Honolulu, HI). Nine sections on average were monitored within each longline deployment with no significant difference $(P<0.001$, ANOVA) in the depth of the observed deepest hook between sections. The average depth of the observed deepest hook was $62 \mathrm{~m}$ (S.D. $=8.5 \mathrm{~m}, n=159$ ), similar to Hawaii-based commercial swordfish fishery, and the deepest hook was always deeper than adjacent hooks ( $n=20$ sections). Mizuno et al. (1998, 1999) demonstrated that the second assumption was not valid for one of their six monitored longlines targeting tuna as the presumed deepest hook was shallower than the two adjacent hooks. However, the longline was deployed in the Equatorial Undercurrent, an area of high horizontal shear, which caused the longline to shoal $70 \%$.

An indirect estimation of sag ratio based on the amount of main line deployed proved problematic. Overall, results were reasonable as shallower swordfish sets had smaller sag ratios and catenary angles than tuna sets, but a portion of the sag ratios could not be calculated. The sag ratio relies on an estimate of the length or speed of main line deployed, which could be biased due to various factors. Method 1 could be biased by a misspecification by the vessel operator of the length of main line deployed or if the longline was not set in a straight line. If the longline was set in a curvilinear direction, then catenary depths would be overestimated in the present study. Method 2 could be biased if either the speed of the line thrower or vessel was misspecified. Alternative methods to

Table 3

Model building for describing longline shoaling as a function of catenary depth and environmental variables (surface current velocity, current shear and wind stress)

\begin{tabular}{|c|c|c|c|c|c|c|c|}
\hline Longline & Null deviance & d.f. & Residual deviance & Residual d.f. & Pseudo- $R^{2}$ & \multicolumn{2}{|l|}{ Parameters } \\
\hline \multicolumn{8}{|l|}{ GLM } \\
\hline Swordfish & 136554.6 & 202 & 103006.1 & 200 & 0.246 & \multirow{3}{*}{\multicolumn{2}{|c|}{$\begin{array}{l}\text { Intercept }=-36.562, \text { linear }=0.9958, \\
\text { quadratic }=-2.331 \mathrm{E}-03, \text { cubic-n.s. } \\
\text { Intercept }=-254.104, \text { linear }=1.784, \\
\text { quadratic }=-3.473 \mathrm{E}-03, \\
\text { cubic }=2.184 \mathrm{E}-06 \\
\text { Intercept }=-106.290, \text { linear }=0.651, \\
\text { quadratic }=-7.456 \mathrm{E}-04, \text { cubic-n.s. }\end{array}$}} \\
\hline Tuna (method 1) & 463011.4 & 197 & 197574.2 & 194 & 0.573 & & \\
\hline Tuna (method 2) & 215381.2 & 254 & 172387.4 & 252 & 0.200 & & \\
\hline Longline & \multicolumn{3}{|c|}{ Explanatory variable } & \multicolumn{2}{|l|}{ Residual d.f. } & Residual deviance & Pseudo- $R^{2}$ \\
\hline \multicolumn{8}{|l|}{ GAM } \\
\hline \multirow[t]{4}{*}{ Swordfish } & \multicolumn{2}{|c|}{ Mean } & & 202 & & 136554.6 & \\
\hline & \multicolumn{3}{|c|}{ Catenary depth } & 197 & & 101640.2 & 0.255 \\
\hline & \multicolumn{3}{|c|}{ Shear } & 192 & & 87931.3 & 0.356 \\
\hline & \multicolumn{3}{|c|}{ Wind stress } & 187 & & 80223.0 & 0.413 \\
\hline \multirow[t]{5}{*}{ Tuna (method 1) } & \multicolumn{3}{|c|}{ Mean } & 197 & & 463011.4 & \\
\hline & \multicolumn{3}{|c|}{ Catenary depth } & 192 & & 191493.6 & 0.586 \\
\hline & \multicolumn{3}{|c|}{ Wind stress } & 187 & & 174854.1 & 0.622 \\
\hline & \multicolumn{3}{|c|}{ Shear } & 182 & & 159131.5 & 0.656 \\
\hline & \multicolumn{3}{|c|}{ Current velocity (Aviso) } & 177 & & 151779.6 & 0.672 \\
\hline \multirow[t]{5}{*}{ Tuna (method 2) } & \multicolumn{3}{|c|}{ Mean } & 254 & & 215381.2 & \\
\hline & \multicolumn{3}{|c|}{ Catenary depth } & 249 & & 168973.6 & 0.199 \\
\hline & \multicolumn{3}{|c|}{ Wind stress } & 244 & & 157291.9 & 0.270 \\
\hline & \multirow{2}{*}{\multicolumn{3}{|c|}{ Shear }} & 239 & & 147079.3 & 0.317 \\
\hline & & \multicolumn{2}{|c|}{ Current velocity (Aviso) } & 234 & & 140687.8 & 0.347 \\
\hline
\end{tabular}

n.s.: not significant. 

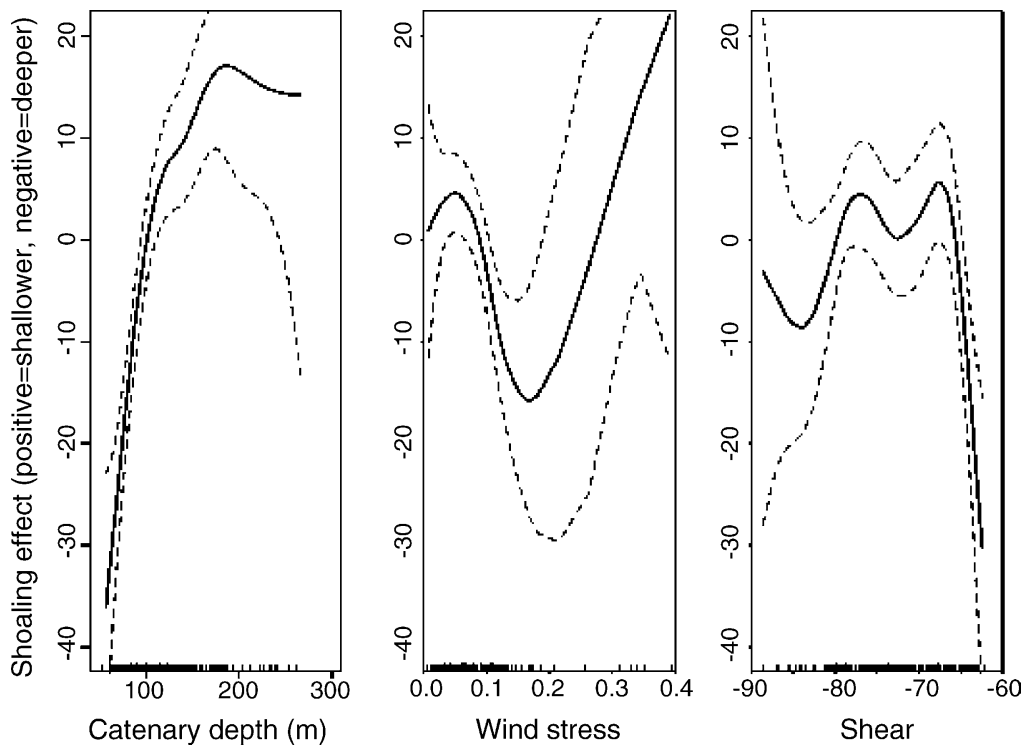

Fig. 3. Generalized additive model (GAM) derived effects of catenary depth, wind stress, and current shear on shoaling of swordfish longline sets. Dashed lines give $95 \%$ confidence bands around the fit.

accurately estimate the rate of main line deployed should be considered for future studies. Feasible methods could include having an observer estimate the time to deploy a segment of the longline with known length or placing an odometer on the line thrower. Estimating the speed of line deployment would be an improvement on method 2 and along with the duration of the longline set without periodic stoppages could result in a less biased sag rate for method 1 .

The sag ratio estimated in this study corresponds to the period of setting the longline; however, the sag ratio may fluctuate throughout the longline operation. Mizuno et al. (1998, 1999) directly and continuously monitored the sagging rate by measuring the horizontal distance between floats with GPS systems. Results indicated that the sag ratio (defined as $H / L$ ) decreased rapidly (range $=6-10 \%$ ) after setting and the longline obtained a deeper settled depth; thereafter the line fluctuated slowly (range $=5-20 \%$ ). The fluctuation corresponded to a potential catenary depth bias of $40 \mathrm{~m}$. The change in sag ratio between setting the longline and the settled depth suggests that catenary depths would be underestimated in the present and previous studies.

Catenary angles for tuna sets in the Hawaii-based fleet are less than those from distant-water fisheries. Shallow tuna sets in the Japanese and Korean distant-water fisheries are thought to have a catenary angle of $72^{\circ}$ (Suzuki et al., 1977; Gong et al., 1989) based on sag ratio of 0.6 (equivalent to a sag ratio of 1.67 in the present study). Catenary angles on deep tuna sets in the Japanese fishery were observed to
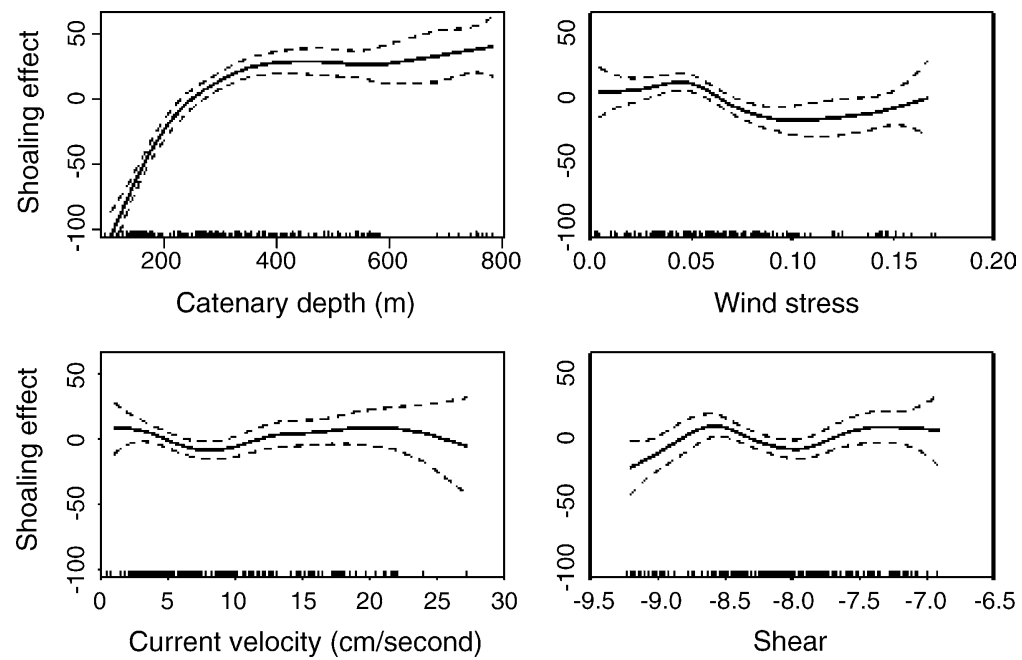

Fig. 4. Generalized additive model (GAM) derived effects of catenary depth, wind stress current velocity, and shear on shoaling of tuna longline sets. Catenary depth estimated by method 1 . Dashed lines give $95 \%$ confidence bands around the fit. 


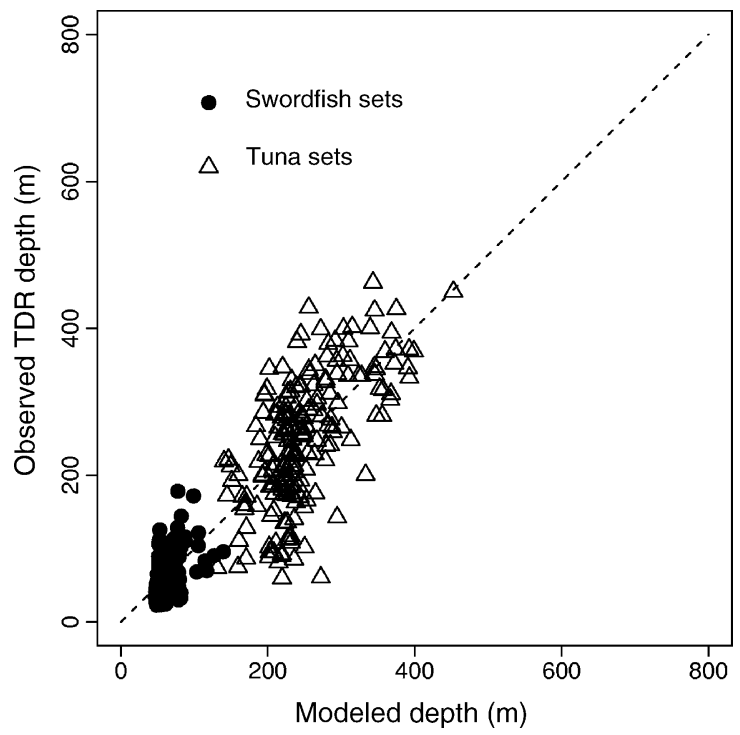

Fig. 5. Comparison of modeled depth and observed depth for swordfish and tuna longline sets.

range from $77^{\circ}\left(\mathrm{sag}\right.$ ratio $=0.5$, Nakano et al., 1997) to $81^{\circ}$ ( sag ratio $=0.4$, Saito, 1973). Using the methodology in the present study, a similar catenary angle $\left(60^{\circ}\right)$ to the Hawaiibased fishery was obtained for the Japanese longline fishery in Micronesia (Bigelow et al., 2002). Our empirical results suggest that the commonly used catenary angle of $72^{\circ}$ is not realistic for the Hawaii-based tuna fishery. If catenary depths were predicted based on an angle of $72^{\circ}$, then the mean predicted depth would increase $\sim 50$ to $394 \mathrm{~m}$ and the median shoaling percentage would increase to $38 \%$. These values are considerably different than our empirically determined values and suggest the need for investigators to verify sag ratios. Observations on the sag ratios for swordfish sets are not available for comparison.

Shallow longline sets reached only $\sim 50 \%$ of their predicted depth while deeper sets reached about $70 \%$. From the results of this study and others (Boggs, 1992; Mizuno et al., 1999), it is apparent that oceanographic factors can grossly deform the shape of longlines, thus reducing the fishing depth of hooks. To try and account for longline shoaling from oceanographic influences, some authors have used correction factors to adjust their estimates of longline fishing depths (Suzuki et al., 1977; Hinton and Nakano, 1996). In their study, Suzuki et al. (1977) estimated a factor of $85 \%$ to correct predicted fishing depths for regular and deep longline gear which Hinton and Nakano (1996) used to correct their depth data. Our study has shown a large discrepancy in the amount of shoaling between shallow and deep longline sets; therefore, correction or adjustment factors should be parameterized for each type of longline set.

Current shear between the surface and the thermocline has been hypothesized as the paramount factor in preventing longline gear from obtaining predicted depths (Boggs, 1992; Mizuno et al., 1998, 1999). Shoaling ranged from 20 to $100 \mathrm{~m}$ for longlines deployed in the equatorial Pacific to depths of 170-200 m, and the degree of shoaling and mainline shape was consistent with the observed vertical shear rather than absolute current speed (Mizuno et al., 1998, 1999). The importance of current shear and velocity in the GAM analysis was consistent with fine-scale longline monitoring as shear had larger explanatory ability than current velocity. Current shear was more important in describing shoaling in swordfish sets. A shear index integrated to $120 \mathrm{~m}$ may be more indicative of the near-surface dynamics of shallow sets, whereas the tuna shear index was integrated to $430 \mathrm{~m}$, and the shoaling dynamics may be confounded by other factors given the deeper water column. There was a general trend for an increase in shoaling in stronger shear environments in the present study, though the Hawaii-based fishery operates in an area with relatively weak shear. We would expect that shoaling would be greater in more dynamic oceanographic areas such as the equatorial Pacific or western boundary currents.

The explanatory ability of the environmental data may have been limited by the scale of the observations or the geometric forcing between the environment and longline set. Mesoscale oceanographic and meteorological data were used in the analysis because no contemporaneous environmental data were collected in association with each longline set. Some of the relationships in the GAM analysis were not expected, such as a shoaling decrease with increasing wind stress, but the relationships may be confounded by the aggregation in space $\left(1-1.5^{\circ}\right)$ and time (weekly to monthly). Additionally, shoaling dynamics are dependent on the direction of the environmental forcing in relation to the longline. For example, wind stress or ocean currents transverse to the longline would be expected to have a greater shoaling effect than in-line or parallel forcing. A simulated monofilament longline basket with five HBF used in the Hawaii-based longline fishery estimated that maximum hook depths were reduced $50 \%$ by a $0.25 \mathrm{~m} / \mathrm{s}$ transverse current and approximately $20 \%$ by a $0.25 \mathrm{~m} / \mathrm{s}$ in-line current (Offcoast and Inc., 1997). The explanatory ability of environmental forcing on longline shoaling may be improved in future studies by incorporating contemporaneous environmental information, though this may restrict analyses to experimental longlines, as commercial fisheries may be difficult to monitor at appropriate spatio-temporal scales.

Our study suggests that estimates of capture depth using traditional catenary equations may be biased by an average of $50 \%$ for swordfish and $30 \%$ for tuna longlines without the benefit of TDRs affixed to longlines. Because of this wide error possibility, interpretation of CPUE variability for stock assessments and possible strategies to minimize bycatch by targeting select fishing depths could be misleading. We therefore suggest fisheries agencies adopt placing TDRs on a percentage of longlines in the commercial fleet to monitor actual fishing depths. While fishing depths should be monitored on commercial longlines, a fine-scale monitoring approach on experimental longlines under a variety of oceanographic conditions may represent a better approach of further improving gear models. 


\section{Acknowledgments}

We thank captains and crews of Hawaii-based commercial longline vessels and the NOAA/NMFS fisheries observers for TDR deployments. Pascal Bach and William Walsh provided suggestions and editorial comments that improved the manuscript. We thank Evan Howell and the NOAA CoastWatch-Central Pacific Node for providing environmental data. The work described in this paper was partly sponsored by the University of Hawaii Pelagic Fisheries Research Program under cooperative agreement number NA17RJ1230 from the National Oceanic and Atmospheric Administration. The views expressed herein are those of the authors and do not necessarily reflect the views of their agencies.

\section{References}

Allen, R.L., Punsley, R.G., 1984. Catch rates as indices of abundance of yellowfin tuna, Thunnus albacares, in the eastern Pacific Ocean. Bull. Int. Am. Trop. Tuna Commun. 18, 301-379.

Bach, P., Dagorn, L., Bertrand, A., Josse, E., Misselis, C., 2003. Acoustic telemetry versus monitored longline fishing for studying the vertical distribution of pelagic fish: bigeye tuna (Thunnus obesus) in French Polynesia. Fish. Res. 60, 281-292.

Behringer, D.W., Ji, M., Leetmaa, A., 1998. An improved coupled model for ENSO prediction and implications for ocean initialisation. Part I. The ocean data assimilation system. Mon. Weather Rev. 126, 1013-1021.

Bigelow, K., Hampton, J., Miyabe, N., 2002. Application of a habitatbased model to estimate effective longline fishing effort and relative abundance of Pacific bigeye tuna (Thunnus obesus). Fish. Oceanogr. 11 (3), 143-155.

Boggs, C.H., 1992. Depth, capture time, and hooked longevity of longlinecaught pelagic fish: timing bites of fish with chips. Fish. Bull. 90, 642-658.

Boggs, C.H., Ito, R., 1993. Hawaii's pelagic fisheries. Mar. Fish. Rev. 55, 69-82.

Bonjean, F., Lagerloef, G.S.E., 2002. Diagnostic model and analysis of the surface currents in the tropical Pacific Ocean. J. Phys. Ocean. 32, 2938-2954.

Brill, R.W., Lutcavage, M.E., 2001. Understanding environmental influences on movements and depth distributions of tunas and billfishes can significantly improve population assessments. In: Sedberry, G. (Ed.), Island in the Stream: Oceanography and Fisheries of the Charleston Bump. Proceedings of the American Fisheries Society Symposium 25. Bethesda, MD, pp. 179-198.

Bullis, H.R., 1955. Preliminary report on exploratory long-line fishing for tuna in the Gulf of Mexico and the Caribbean Sea. Part 1. Exploratory fishing by the Oregon. Commer. Fish. Rev. (Washington, DC) 17 (10), $1-15$.

Gong, Y., Lee, J-U., Kim, Y-S., Yang, W-S., 1989. Fishing efficiency of Korean regular and deep longline gears and vertical distribution of tunas in the Indian Ocean. Bull. Korean Fish. Soc. 22, 86-94.

Graham, J.J., Stewart, D.D., 1958. Estimating maximum fishing depth of longline gear with chemical sounding tubes. U.S. Dept. Interior, Fish Wildl. Ser., Spec. Scien. Rep. Fish. No. 285, 16 pp.

Grundinin, V.B., 1989. On the ecology of yellowfin tuna (Thunnus albacares) and bigeye tuna (Thunnus obesus). J. Ichthyol. 29 (6), $22-29$.

Hanamoto, E., 1974. Fishery oceanography of bigeye tuna. I. Depth of capture by tuna longline gear in the eastern tropical Pacific Ocean. La Mer 13, 58-71.
Hanamoto, E., 1987. Effect of oceanographic environment on bigeye tuna distribution. Bull. Jpn. Soc. Fish. Oceanogr. 51, 203-216.

Herron, R.C., Leming, T.D., Li, J., 1989. Satellite-detected fronts and butterfish aggregations in the northeastern Gulf of Mexico. Cont. Shelf Res. 9, 569-588.

Hinton, M.G., Nakano, H., 1996. Standardizing catch and effort statistics using physiological, cological, or behavioral constraints and environmental data, with an application to blue marlin (Makaira nigricans) catch and effort data from Japanese longline fisheries in the Pacific. Bull. Int. Am. Trop. Tuna Commun. 21, 171-200.

Ito, R.Y., Dollar, R.E., Kawamoto, K., 1998. The Hawaii-based longline fishery for swordfish. In: Barrett, I., Sosa-Nishizaki, O., Bartoo, N. (Eds.), Biology and Fisheries of Swordfish, Xiphias gladius. Papers from the International Symposium on Pacific Swordfish, NOAA Tech. Rep. NMFS 142. Ensenada, Mexico, December 11-14, 1994, pp. 77-88.

Laurs, R.M., Lynn, R., Nishimoto, R., Dotson, R., 1981. Albacore trolling and longline exploration in the eastern North Pacific waters during mid-winter 1981. NOAA Technical Memorandum NMFS, NOAATM-SWFC-10.

Mizuno, K., Okazaki, M., Watanabe, T., Yanagi, S., 1996. A micro bathythermograph system for tuna longline boats in view of large scale ocean observing system. Bull. Nat. Res. Inst. Far Seas Fish. 33, $1-15$.

Mizuno, K., Okazaki, M., Miyabe, N., 1998. Fluctuation of longline shortening rate and its effect on underwater longline shape. Bull. Nat. Res. Inst. Far Seas Fish. 35, 155-164.

Mizuno, K., Okazaki, M., Nakano, H., Okamura, H., 1999. Estimation of underwater shape of tuna longlines with micro-bathythermographs. Int. Am. Trop. Tuna Commun. Spec. Rep. 10, 35 pp.

Nakano, H., Okazaki, M., Okamoto, H., 1997. Analysis of catch depth by species for tuna longline fishery based on catch by branch lines. Bull. Nat. Res. Inst. Far Seas Fish. 34, 43-62.

Nishi, T., 1990. The hourly variations of the depth of hooks and the hooking depth of yellowfin tuna (Thunnus albacares), and bigeye tuna (Thunnus obesus), of tuna longline in the eastern region of the Indian Ocean. Mem. Fac. Fish. Kagoshima Univ. 39, 81-98.

Offcoast Inc., 1997. Modeling gear configuration of longlines. Report No: OCI-97-202, 201 Hamakua Drive, Suite C-107, Kailua, HI 96734, USA, p. 7.

Okazaki, M., Mizuno, K., Watanabe, T., Yanagi, S., 1997. Improved model of micro bathythermograph system for tuna longline boats and its application to fisheries oceanography. Bull. Nat. Res. Inst. Far Seas Fish. 34, 25-41.

Picot N., Case K., Desai S., Vincent, P., 2003. AVISO and PO.DAAC User Handbook, IGDR and GDR Jason Products. SMM-MU-M5-OP13184-CN (AVISO), JPL D-21352 (PO.DAAC).

Podestá, G.P., Browder, J.A., Hoey, J.J., 1993. Exploring the association between swordfish catch rates and thermal fronts on U.S. longline grounds in the western North Atlantic. Cont. Shelf Res. 13, 253277.

Polovina, J., Kleiber, P., Kobayashi, D., 1999. Application of TOPEXPOSEIDON satellite altimetry to simulate transport dynamics of larvae of spiny lobster, Panulirus marginatus, in the Northwestern Hawaiian Islands, 1993-1996. Fish. Bull. 97, 132-143.

Power, J.H., May, L.N., 1991. Satellite observed sea-surface temperatures and yellowfin tuna catch and effort in the Gulf of Mexico. Fish. Bull. 89, 429-439.

Saito, S., 1973. Studies on fishing of albacore, Thunnus alalunga (Bonnaterre) by experimental deep-sea tuna long-line. Mem. Fac. Fish. Hokkaido Univ. 21, 107-185.

Saito, S., 1975. On the depth of capture of bigeye tuna by further improved vertical long-line in the tropical Pacific. Bull. Jpn. Soc. Sci. Fish. 41, 831-841.

Saito, S., Ishii, K., Yoneta, K., 1970. Swimming depths of large sized albacore in the South Pacific Ocean. 1. Fishing of albacore by newly designed vertical longline. Bull. Jpn. Soc. Sci. Fish. 36, 578-584. 
Squire, J.L., 1985. Relationship of sea surface temperature isotherm patterns off northwestern Mexico to the catch of striped marlin, Tetrapturus audax, off southern California. Mar. Fish. Rev. 47, 4347.

Squire, J.L., 1987. Relation of sea surface temperature changes during the 1983 El Niño to the geographical distribution of some important recreational pelagic species and their catch temperature parameters. Mar. Fish. Rev. 49, 44-57.

Suzuki, Z., Warashina, Y., Kishida, M., 1977. The comparison of catches by regular and deep tuna longline gears in the western and central equatorial Pacific. Bull. Far Seas Fish. Res. Lab. 15, 51-89.
Venables, W., Ripley, B., 1999. Modern Applied Statistics with S-Plus, 3rd ed. Springer, New York.

Ward, P.J., Ramirez, C.M., Caton, A.E., 1996. Preliminary analysis of factors affecting catch rates of Japanese longliners in the north-eastern AFZ. In: Ward, P.J. (Ed.), Japanese Longlining in Eastern Australian Waters. Bureau of Resource Sciences, Canberra, pp. 145-183.

Yoshihara, T., 1951. Distribution of fishes caught by the long line. II. Vertical distribution. Bull. Jpn. Soc. Sci. Fish. 16, 370-374.

Yoshihara, T., 1954. Distribution of catch of tuna longline. IV. On the relation between $K$ and $\varphi_{0}$ with a table and diagram. Bull. Jpn. Soc. Sci. Fish. 19, 1012-1014. 